\title{
Implantação do meliponário como componente agroflorestal no campus Picuí,
} Paraíba

\author{
Cosma Layssa Santos Gomes ${ }^{1}$, Djair Alves de Melo ${ }^{1}$, José Jean Gonçalves ${ }^{2}$, George Henrique Camêlo Guimarães ${ }^{1}$, \\ Iara Gabriela de Lima Gomes ${ }^{1}$, Andreza Lima Cunha ${ }^{1}$
}

\begin{abstract}
${ }^{1}$ Instituto Federal da Paraíba, layssasnts@gmail.com; djairifpb@gmail.com; guimaraesghc@gmail.com; iaragabriella.nf@gmail.com; andrezalima1533@gmail.com; ${ }^{2}$ EMATER-RN, jeanapicultor@gmail.com.
\end{abstract}

\begin{abstract}
RESUMO: O projeto de implantação do meliponário associado com o componente de Sistema Agroflorestais foi implantado no Campus Picuí do Instituto Federal de Educação, Ciência e Tecnologia da Paraíba, localizado sob as coordenadas geográficas (Latitude de $6^{\circ} 32^{\prime} 50^{\prime \prime} \mathrm{N}$, Longitude $36^{\circ} 21^{\prime} 44^{\prime \prime} \mathrm{W}$ ). A criação de abelhas sem ferrão pode ser uma atividade atrativa ao agricultor de baixa renda, podendo gerar impactos positivo na geração de renda e qualidade de vida. Portanto, objetivou-se com trabalho implantar um meliponário nas dependências do Campus Picuí como um componente de um sistema agroflorestal. A experiência foi vivenciada pelos alunos responsáveis pelo manejo do Bosque florestal do Campus Picuí do curso superior em Agroecologia. A atividade de manejo e implantação do meliponário esteve ligada as atividades extracurricular da disciplina de Sistemas Agroflorestais e Produção Animal III. A implantação do projeto atendeu a uma demanda postas pelo professor titular da disciplina juntamente com o Técnico Agropecuário da Emater-RN com o intuito de proporcionar oportunidade aos alunos das disciplinas relacionadas ao projeto como os demais alunos envolvidos. Assim disponibilizando um espaço de área de estudos práticos, como também em ações futuras promover dias de campo aos produtores locais. Ficou evidente que a associação da meliponicultura aos sistemas agroflorestais, contribui com o aumento da produção e qualidade do mel produzido. Dessa forma, a Meliponicultura pode servir como alternativa socioeconômica aos alunos de agroecologia como também as comunidades circunvizinhas ao Campus Picuí-PB.
\end{abstract}

PALAVRAS-CHAVE: Jandaíra; Abelha mosquito; Agricultura familiar; Semiárido; Produção de mel.

\section{INTRODUÇÃO}

O agricultor do semiárido paraibano pode tomar como prática econômica a criação de abelhas sem ferrão gerando renda e qualidade de vida para suas famílias. As abelhas sem ferrão estão dispostas na ordem Hymenoptera por sua natureza apresentam uma habilidade polinizar os mais diversos ecossistemas. As abelhas mais conhecidas no Brasil estão as Apis mellífera e as nativas sem ferrão, ambas conhecidas e exploradas pelos indígenas desde os tempos antigos (CORTOPASSI-LAURINDO et al., 2006).

A criação de abelhas Apis melliffera ou sem ferrão, apresenta-se como oportunidade para o homem produtor rural na geração de renda sem interferir no ecossistema da sua propriedade gerando renda e qualidade de vida aos seus familiares (FREITAS et al., 2004). Os efeitos socioeconômicos na pratica da meliponicultura pode mitigar as dificuldades encontradas pelo homem do campo. A atividade da meliponicultura gera inúmeras oportunidades de geração de rendas nas propriedades rurais, reduzindo o êxodo rural e proporcionando qualidade de vida no âmbito da agricultura familiar (EMBRAPA, 2003).

A importâncias das abelhas está diretamente ligada à sua interpendência da flora que habita, a polinização das plantas nativas ou de interesse agronômico é garantida de acordo com o compasso de visitas realizadas pelas abelhas, assim garantindo a mantença da produção como a perpetuação das espécies (PEGORARO e ZILLER, 2003).

Desta forma, a introdução da meliponicultura através de atividades educacionais através da implantação de um meliponário no Campus Picuí-PB, visando promover o desenvolvimento técnico e socioeconômico dos alunos do Curso Superior em Agroecologia, bem como estimular a preservação das abelhas polinizadoras e, consequentemente, da área verde do bosque florestal construído em associação com o componente agroflorestal, apresenta grande importância.

Portanto, objetivou-se com trabalho implantar um meliponário nas dependências do Campus Picuí como um componente de um sistema agroflorestal.

\section{MATERIAL E MÉTODOS}

O trabalho foi desenvolvido no mês de junho de 2019 no Instituto Federal de Educação, Ciência e Tecnologia da Paraíba, campus de Picuí - PB. Localizado sob as coordenadas geográficas (Latitude de $6^{\circ} 32^{\prime} 50^{\prime \prime} \mathrm{N}$, Longitude $36^{\circ}$ 21,44" W. De acordo com a classificação de Köppen, o clima do município de Picuí-PB é do tipo Bsh semiárido quente, com chuvas de verão e com período de estiagem de 7 a 8 meses. A pluviometria é em torno de $339,1 \mathrm{~mm}$ e temperatura variando de $23^{\circ} \mathrm{C}$ a $25^{\circ} \mathrm{C}$, com vegetação predominante de Caatinga (BELTRÃO, 2005). 
GOMES, C. L. S. et al. Implantação do meliponário como componente agroflorestal no campus Picuí, Paraíba. In: II Congresso Paraibano de Agroecologia \& IV Exposição Tecnológica, 2019. Anais... Caderno Verde de Agroecologia e Desenvolvimento Sustentável, Pombal, v. 9, n.7, e-6704, 2019.

A experiência de implantação do primeiro meliponário do Campus Picuí foi vivenciada pelos alunos responsáveis pelo manejo do Bosque florestal do Campus Picuí do curso superior em Agroecologia do IFPB CampusPicuí, a atividade de manejo e implantação do meliponário está ligada as atividades extracurriculares da disciplina de Sistemas Agroflorestais e Produção Animal III. A implantação do projeto veio atender a uma demanda postas pelo professor titular da disciplina juntamente com o Técnico Agropecuário da Emater-RN com o intuito de proporcionar oportunidade aos alunos das disciplinas relacionadas ao projeto como os demais alunos envolvidos, assim disponibilizando um espaço de área de estudos práticos, como também em ações futuras promover dias de campo aos produtores locais. Portanto, suprindo a necessidades de uma área experimental que venha beneficiar os alunos do Curso de Agroecologia.

\section{RESULTADOS E DISCUSSÃO}

O repasse das técnicas agroflorestais e multiplicação de exame, manejo e instalação do meliponário se deu nos seguintes momentos:

Momento 1 - Entre os meses de março e maio de 2019 foi realizado o manejo das árvores de Algaroba (Prosopis juliflora) e Jurema Preta (Mimosa tenuiflora) da área agroecológica com as técnicas de rebaixamento e raleamento da Caatinga, assim o demonstrou-se a importância do manejo de Caatinga de forma prática. Formando um pequeno bosque proporcionando um espaço adequado para o bem-estar para fauna como atividades futuras como identificação de espécies florestais, prática da Ornitologia, associação animal-floresta, conforme (Figura 1 A e B).

Figura 1 - A Preparo da área, B - Manejo finalizado para a implantação do meliponário.

Fonte: Azevedo (2019)

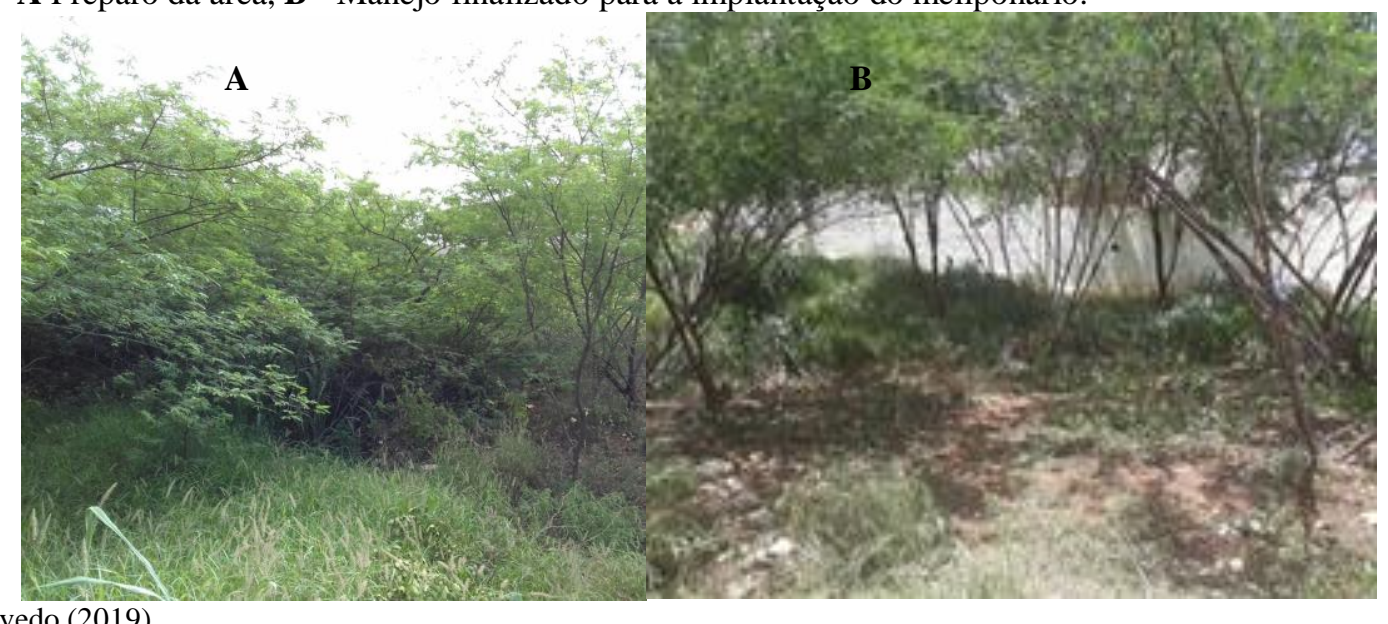

Momento 2 - Conceito e importância da meliponicultura com bases agroecológicas • benefícios socioeconômicos da produção do mel para o ser humano • conceito da criação de abelhas sem ferrão • diferença entre gêneros de abelhas sem ferrão • importância da integração dos animais à unidade familiar de produção agroecológica, (Figura 2).

Figura 2 - Socialização dos conceitos técnicos e apresentação da importância da meliponicultura com bases agroecológicas.

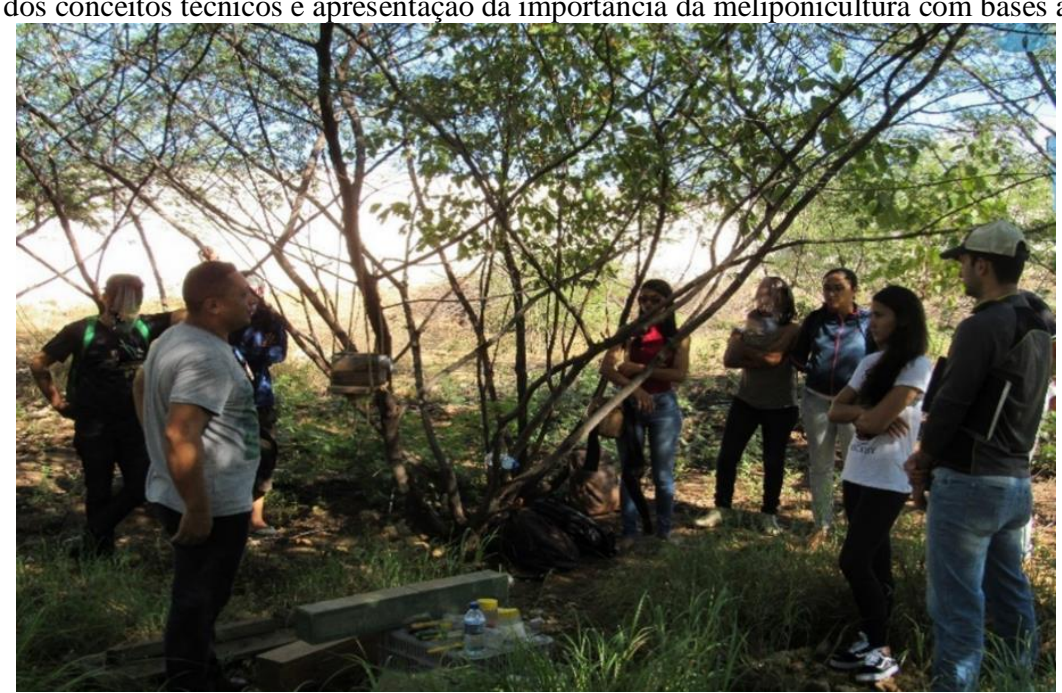

Fonte: Melo (2019) 
GOMES, C. L. S. et al. Implantação do meliponário como componente agroflorestal no campus Picuí, Paraíba. In: II Congresso Paraibano de Agroecologia \& IV Exposição Tecnológica, 2019. Anais... Caderno Verde de Agroecologia e Desenvolvimento Sustentável, Pombal, v. 9, n.7, e-6704, 2019.

Momento 3 - identificação das caixas utilizadas na meliponicultura, reconhecimento da arquitetura dos ninhos e indivíduos, divisão e transferência dos enxames para as caixas (colmeias), instalação do meliponário definitivo com as caixas nos locais pré-definidos como ventilação, iluminação e proteção adequada, (Figura 3).

Figura 3 - Identificação das caixas utilizadas na meliponicultura (3a); reconhecimento da arquitetura dos ninhos e indivíduos (3b) e instalação do meliponário definitivo com as caixas nos locais pré-definidos como ventilação, iluminação e proteção adequada (3c).

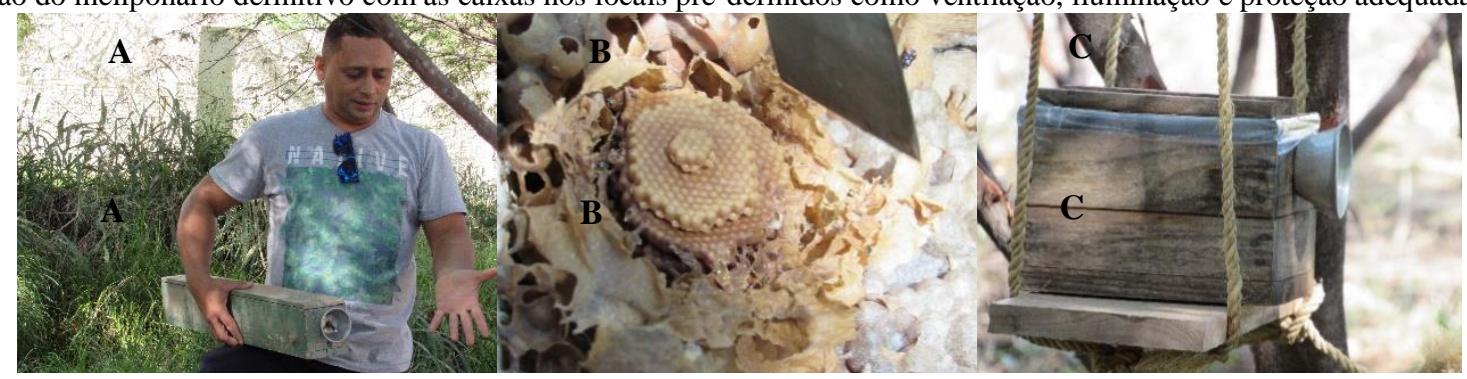

Fonte: Melo (2019)

De acordo com a Confederação Brasileira de Apicultura (CBA), define com a criação de abelhas nativas (sem ferrão) como meliponicultura a criação racional destas abelhas, a primeira vez que esse termo foi utilizado no Brasil se deu em 1953 pelo pesquisador Nogueira-Neto. Dentre as principais abelhas sem ferrão estão a uruçu verdadeira, uruçu amarela, jata', mandaçaia e tiúba amarela, produtoras de um mel com sabor e aroma diferenciado por suas características fisioquímicas com influência direta na saúde humana (NOGUEIRA-NETO, 1997).

A implantação do meliponário em áreas estratégicas para a disseminação do conhecimento sobre a produção de mel é de fundamental importância para a agricultura familiar, gerando renda e qualidade de vida aos pequenos produtores. A prática dentro das disciplinas Sistemas Agroflorestais e Animal III propiciou aos alunos envolvidos a oportunidade de conciliar teoria e prática. Todas práticas realizadas serviram para reforçar a importância da realização de trabalhos na área destinadas ao Curso Superior de Agroecologia.

A socialização das técnicas da meliponicultura nos órgãos de difusão tecnológica entre os agricultores desperta o interesse na criação de abelhas sem ferrão pelas características de passividade e relação direta com a agroecologia. Os agricultores familiares a cada dia buscam capacitação junto aos órgãos de fomento com a intenção de colocar em prática a exploração desta atividade em crescente desenvolvimento (MAGALHÃES e VENTURIERI, 2010)

Esta atividade proporcionou aos futuros tecnólogos em Agroecologia vivenciar a realidade de uma instalação de um meliponário, tendo em vista que, a maioria dos alunos não tem contato direto com esse tipo de atividade, se mostram bastante interessados pela área de meliponicultura gerando perspectiva de geração de renda a médio a longo prazo. Uma vez que, atualmente a assistência técnica local encontra-se defasada, assim os futuros agroecólogos poderão repassar o conhecimento aos agricultores da região.

Um trabalho dessa grandeza estabelece uma relação de reciprocidade entre profissional/agricultor, a partir deste revela-se que todos os envolvidos têm um pouco para ensinar - aprender, que não é apenas quem está inserido em uma academia, mas a experiência do dia a dia também capacita as pessoas, muitas vezes estes mostram resistência diante das novas tecnologias, cabe ao profissional convencê-los que pode dar certo, e para isso é necessário conhecer esse meio rural (QUEIROZ et al., 2015).

Ao término da capacitação foi perceptível a satisfação da equipe repercussão e comunidade local e redes sociais, onde os agricultores ficaram curiosos e querendo saber quais critérios seriam necessários para que os mesmos fossem beneficiados.

Atividades desta natureza traz à tona a importância do profissional das ciências agrárias na contribuição socioeconômica da sociedade. Fica evidente a importância da produção de alimentos livres de qualidade nutricional favorecendo uma alimentação de qualidade e uma melhor qualidade de vida (QUEIROZ, 2015).

Um sistema desta natureza faz uma diferença considerável na região semiárida, pois viabiliza a produção de alimentos para a população de baixa renda, com um sistema prático na exploração zootécnica otimizando a produção, de mel de boa qualidade, tornando-se um fator preponderante para a agricultura familiar do Curimataú Paraibano. Por ser uma tecnologia teoricamente de fácil aplicação, visa além do crescimento econômico da região, como também a qualidade de vida do agricultor familiar.

\section{CONCLUSÕES}

Ficou evidente que a associação da meliponicultura aos sistemas agroflorestais, contribuir com o aumento da produção e qualidade do mel produzido. produtor.

Os participantes observaram que a produção de alimentos (mel) favorecer a segurança alimentar e nutricional do

Dessa forma, a Meliponicultura pode servir como alternativa socioeconômica aos alunos de agroecologia como também as comunidades circunvizinhas ao Campus Picuí-PB. 
GOMES, C. L. S. et al. Implantação do meliponário como componente agroflorestal no campus Picuí, Paraíba. In: II Congresso Paraibano de Agroecologia \& IV Exposição Tecnológica, 2019. Anais... Caderno Verde de Agroecologia e Desenvolvimento Sustentável, Pombal, v. 9, n.7, e-6704, 2019.

\section{REFERÊNCIAS}

BELTRÃO, B. A.; MORAIS, F.; MASCARENHAS, J. C.; MIRANDA, J. L. F.; SOUSA JÚNIOR, L. C.; MENDES, V.A. Projeto Cadastro de Fontes de Abastecimento por Água Subterrânea Estado de Paraíba. Diagnóstico do município de Picuí. Recife, setembro de 2005.

CORTOPASSI-LAURINO, M.; IMPERATRIZ-FONSECA, V. L.; ROUBIK, D. W.; DOLLIN, A.; HEARD, T.; AGUILAR, I. B.; VENTURIERI, G. C.; EARDLEY, C.; NOGUEIRA-NETO, P. Global Meliponiculture: challenges and opportunities. Apidologie, v. 37, 2006.

EMBRAPA. Produção de Mel. Brasília: Empresa Brasileira de Pesquisa Agropecuária - EMBRAPA, 2003.

FREITAS, D. G. F. et al. Nível tecnológico e rentabilidade de produção de mel de abelha (Apis mellifera) no Ceará. Revista de Economia e Sociologia Rural, Rio de Janeiro, v.42, n.1, p.171-188, jan/mar 2004.

KÖPPEN, W.; GEIGER, R. "Klimate der Erde. Gotha: Verlag Justus Perthes”. Wall-map 150cmx200cm. 1928.

MAGAlHÃes, T. L. \& VEnTURIERI, G. C. Aspectos Econômicos da Criação de Abelhas Indígenas Sem Ferrão (Apidae: Meliponini) no Nordeste Paraense. 37p. Belém, PA: Embrapa, 2010.

NOGUEIRA-NETO, P. Vida e Criação das Abelhas Indígenas sem Ferrão. 447p. São Paulo, SP: Nogueirapis, 1997.

PEGORARO, A. e ZILLER, S.R. Valor Apícola das Espécies Vegetais de duas Fases Sucessionais da Floresta Ombrófila Mista, em União da Vitória Paraná - Brasil. Boletim de Pesquisa Florestal, Colombo, n.47, p.69-82, jul/dez. 2003.

QUEIROZ, M. J.; MELO, D. A.; FREIRE, J. L. O.; ALBUQUERQUE, R. S. Implantação do projeto pais no Sítio Cardeiro município de Picuí - PB. VII Simpósio brasileiro sobre meio ambiente e desenvolvimento sustentável do semiárido. Anais. Mossoró-RN. 2015.

\section{AGRADECIMENTOS}

Apoio financeiro: Fundação de Apoio à Pesquisa do Estado da Paraíba - FAPESQ. 